\title{
MAXIMUM TENSION DEVELOPED BY THE POSTERIOR ADDUCTOR MUSCLE OF THE GIANT CLAM, TRIDACNA GIGAS (LINNÉ)
}

\author{
DONALD M. MAYNARD* and WILLIAM BURKE \\ The University of Michigan, Ann Arbor; and the University of Sydney, Australia
}

(Received 16 April 1970)

\begin{abstract}
The isometric closing tension of the posterior adductor muscle of giant clams, Tridacna gigas (L.), was measured under natural conditions on reefs and under more controlled conditions aboard the R/V Alpha Helix.

2. Active tension increased with muscle length up to the maximum in vivo length.

3. Tensions per unit cross section of the adductor averaged $8 \cdot 0 \pm 1 \cdot 1 \mathrm{~kg} / \mathrm{cm}^{2}$ at $120 \%$ minimal length (minimal length $=$ length at full valve closure) when the cross section area is the area at this length. If the tension is calculated with respect to the cross section area at minimal length the value becomes $6.7 \pm$ $0.9 \mathrm{~kg} / \mathrm{cm}^{2}$. The values were relatively constant for clams ranging in size from 6 to $212 \mathrm{~kg}$ total weight.

4. The total tension developed by the posterior adductor in large clams was well over $500 \mathrm{~kg}$.
\end{abstract}

\section{INTRODUCTION}

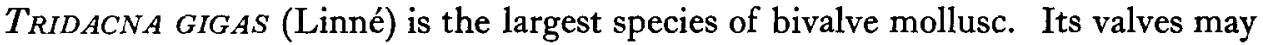
attain lengths in excess of four and one half feet $(1.37 \mathrm{~m})$ and weights of more than $550 \mathrm{lb}$ (pair) or about $250 \mathrm{~kg}$ (Rosewater, 1965). The total weight of such a clam, including valves and viscera, would be of the order of $300 \mathrm{~kg}$. On the Great Barrier Reef adult Tridacna often occur on patches of sand among heads of reef coral. Although young $T$. gigas and smaller species are attached to coral or rock substrate by a byssus, the adult $T$. gigas normally lies free, umbo down, and remains in place because of its great mass. The valves usually gape open several inches, exposing the fleshy folds of the algae-bearing mantle. Upon appropriate stimulation, however, the valves may close, apparently with considerable force.

We were interested in measuring tension developed by the posterior adductor because although it is the largest known molluscan muscle, the clam's natural habit of gaping suggests that it seldom contracts fully. We wondered whether it was capable of developing specific tension $/ \mathrm{cm}^{2}$ (force) comparable to that found in other molluscan adductors (Marceau, 1909). Vaillant measured Tridacna closing tensions in 1865 , but the results were fragmentary. This paper reports our measurements of the closing force of the posterior adductor of $T$. gigas.

* Present address: The Department of Biology, University of Oregon Eugene, Oregon 97403. 


\section{MATERIALS AND METHODS}

Thirteen individuals ranging in total weight from 6 to $212 \mathrm{~kg}$ and in maximum valve length from 31 to $93 \mathrm{~cm}$ were examined. They were collected either on Clack Reef, one of the Flinders Island group in northern Queensland, or on the Great Barrier Reef due east of the group. Smaller clams were maintained in good condition in tubs of running sea water on the deck of the R/V Alpha Helix and were studied over a period of days. Measurements on larger clams were of necessity made in air on deck shortly after bringing them aboard (within $\frac{1}{2}-1 \mathrm{hr}$ ) and immediately after washing them down with fresh sea water. Rosewater's monograph on Pacific Tridacna, 1965, was used as the basis for field identification.

\section{Body Weights}

Cleaned valves and soft parts or viscera were weighed separately. The viscera weight (64 \pm 9 per cent) was always less than the difference between the total weight of the clam and the weight of the valves. This discrepancy was due in part to the loss of an unmeasured volume of sea water present in mantle cavities after draining and included in the total weight, and in part to the unavoidable loss of an unknown volume of hemolymph during removal of the viscera from the valves.

\section{Muscle parameters}

Weight. The posterior adductor muscle was dissected free of surrounding tissue and weighted with a spring scale. Values ranged from $0.09 \mathrm{~kg}$ to $1.45 \mathrm{~kg}$.

Length. The isolated adductor forms a muscular column with slanted ends. The length, measured from mid-point to mid-point of the column while it lay on its side, ranged from $8 \mathrm{~cm}$ to $22 \mathrm{~cm}$. On the average, this is $78 \pm 5$ per cent of the minimum estimated in situ muscle length at full valve closure. True muscle length at various valve openings was estimated from shell dimensions (see below).

Cross-section area. The cross-section of the adductor is normally elliptical, but since circumference measurements were more easily obtained than diameters, and since the major and minor axes were relatively similat (major axis/minor axis $=1.2$ at most) we felt justified in assuming a circular cross section for calculations of area. Such areas estimated from circumference measurements on the isolated muscle ranged from 13 to $69 \mathrm{~cm}^{2}$.

As a check on the reliability of the linear measurements, the volume of each isolated muscle calculated from length and circumference measurements was compared with the measured weight. The mean weight/volume ratio was 1.117 with a standard deviation of 0.038 . The density value seems reasonable, and the variance lies well within expected measurement error. We assume, therefore, that our dimensional values are satisfactory for present purposes.

If muscle volume remains constant, then any change in muscle length will be associated with a reciprocal change in muscle cross section. Estimated cross section values at minimum isolated length were therefore reduced proportionally as length increased to in situ values.

\section{Morphology and histology}

The posterior adductor muscle of Tridacna, as with most bivalve molluscs, is composed of two parts: a smaller portion which appears white in incident illumination, and a larger portion which appears gray or translucent. In a small number of clams these two portions were dissected and weighed separately. The white muscle represented $15 \pm 4 \%$ of the total musclc mass, and therefore approximately 15 per cent of the cross section area. In other bivalves (Marceau, 1909; Abbott \& Lowy, 1956) the smaller white portion appears to contract more slowly while the gray portion is fast muscle.

Pieces of both the white and gray portions were fixed, embedded in paraffin and sectioned. The muscle fibers are parallel, arranged in relatively large bundles with little intervening connective tissue. The fiber diameters were variable with an upper value of about $8 \mu$; length of muscle fibers was undetermined, but it seems unlikely that a single fiber 
extends the full length of the muscle, up to $22 \mathrm{~cm}$. Spiral striations were evident in gray fibers only.

\section{Tension measurements}

Valve closure in Tridacna normally occurs in a series of jerks, each representing a twitch of the adductor. Full closure or maximal isometric tension at any given valve opening comes only after repeated or unusually intense stimulation. Once attained, however, such tension is normally maintained as long as stimulation continues. With cessation of stimulation, the adductor gradually relaxes and the valves open after periods of several tens of seconds or minutes.

Active isometric tension developed at the edges of the valves was measured in two ways:

1. The clam was placed in normal position, umbo down, and the valves were then forcibly pulled apart while the tension required to open them to specific distances was measured with a spring scale of the appropriate capacity. In order to ensure maximal contraction the visceral mass and the mantle were stimulated mechanically with a blunt probe during the measurements, thus adding to the effects produced by stretch. Smaller clams were held in tubs of sea water during such measurements, but the larger ones were located in air on the open deck. Opening the larger clams also required the use of block and tackle and a winch.

The measurements obtained by this method thus represent isometric tensions developed by a contracted muscle as it is gradually stretched without interposed full relaxation. We refer to the forces obtained in this way as "pulling tensions". In most instances the muscle eventually ruptured before maximal rest lengths were reached.

2. In the second method, a hydrostatic pressure device was inserted between the valve edges of a partially relaxed clam and the force developed by the clam in further closing to a predetermined gape during mechanical stimulation was measured. We term forces measured in this way as "closing tension". These measurements were made on smaller individuals in aquaria or tubs on board the $\mathrm{R} / \mathrm{V}$ Alpha Helix, or on the larger clams in their natural habitat on the reefs. Most of the latter measurements were made at low tide on Clack Reef when the upper edges of the larger Tridacna were either just below the surface or protruded a few inches above. In some cases, however, measurements were made on clams in 10-15 ft depths just within the outer barrier reef. In general the measuring device could not be inserted between the valves without causing partial closure as a consequence of shadow or movement-induced reflexes. This was particularly troublesome with field measurements on the larger clams, and active tension developed at full rest length was not obtained.

Ligament tension and opening forces. The closing force of the posterior adductor is opposed by the opening force of the elastic ligament of the hinge, and when the clam is upright in its normal position, by a component of the weight of the valves and viscera. The viscera contribute relatively little however; they weigh 20-30 per cent of the values in air and even lcss in water. Their position in the lower half of the valves near the umbo further reduces their relative opening force. The estimated opening forces obtained from eviscerated clams are therefore probably reasonably accurate. Immediately after evisceration, the valves were placed upright in normal position, and the total forces tending to open the clam (ligament plus valve mass) were estimated by determining the force necessary to close the valves to specified extents.

The structure of the mantle and visceral mass suggest that they might exert some passive resistance at wide valve openings. We also wished to examine the passive properties of the muscle. To do this, one clam was anesthetized with MS $222(0.2 \%$ solution $)$ in sea water, and then pulled fully open.

\section{Geometry and correction factors}

The tensions measured at the edges of the valve do not represent the true tensions exerted by the muscle. Figure 1 diagrams the forces and vectors involved. Four linear 
measurements from each set of valves were made: (1) the linear distance from the axis of the hinge to the centerpoint of the scar of the posterior adductor $(x),(2)$ the linear distance from the axis of the hinge to the edge of the valve where the opening tension was applied $(y),(3)$ the distance of the perpendicular running from the vertical midline at full valve closure to the edge of the valve $(u)$, and (4) the perpendicular distance from the vertical midline at full valve

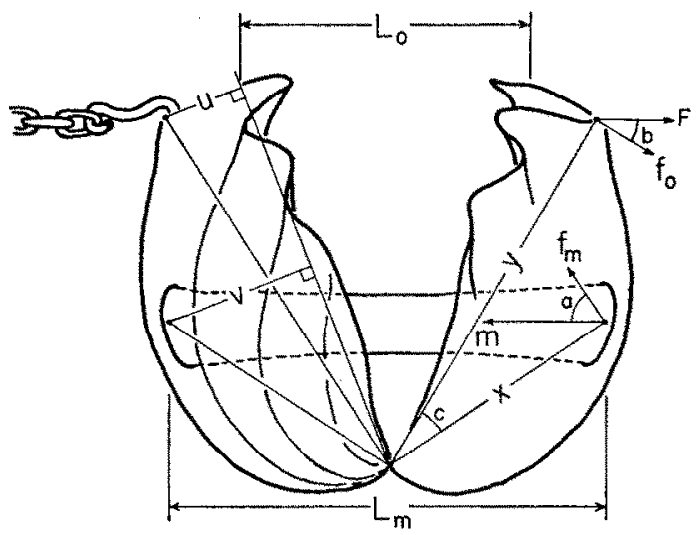

Frg. 1. Diagram of measurements and force vectors, $u, v, x, y$, linear valve dimensions measured in each clam. $L_{0}$, extent of valve gape measured between two points on edge chosen so that $L_{0}=0$ at full valve closure. $L_{m}$, length of posterior adductor muscle measured from mid-point to mid-point of attachment, $L_{m}=2(x)(\sin a)$. $F$, applied opening force. $f_{0}$, component of opening force producing gape, $f_{0}=$ (F) $(\cos b) . m$, force exerted by muscle. $f_{m}$, component of muscular force opposing valve gape, $f_{m}=(m)(\cos a)$. Where no net movements occurs, opening and closing forces are in equilibrium, $(x)\left(f_{m}\right)=(y)\left(f_{0}\right)$. Muscular force, $m$, therefore is equivalent to $(F)(\cos b / \cos a)(y / x)$. The angle $c$ and the ratio $y / x$ are specific for each individual clam.

closure to the center of the posterior adductor scar $(v)$. From these it is possible to derive values of the ratio $y / x$ (average value $=1.45 \pm 0.098$ ) and values of the angle $c$ (average value $=16 \cdot 1 \pm 3 \cdot 8^{\circ}$ ). These indices are specific for each valve. Using the valve opening distance, $L_{0}$, taken during the experiment to calculate values of angles $a$ and $b$ permits estimates of the mechanical advantage between muscle attachment and valve edge for varying degrees of opening, e.g. typically 1.5 at closure, 1.63 at an opening of $30^{\circ}$. Muscle length in situ was considered equivalent to $2(x)(\sin a)$.

Appropriate mechanical advantages and muscle lengths were calculated for all tension measurements on individual clams. Specific tension at a given length is expressed in terms of $\mathrm{cm}^{2}$ muscle cross section at that length. It proved more accurate to use the minimum in situ muscle length at full closure as a standard than to use the more usual "rest" or maximum in situ length because the extent of valve opening was not a constant percent of the minimum muscle length. Rather it depended upon valve, hinge, and hinge tooth configurations which varied according to the growth conditions of the individual clam.

\section{RESULTS}

\section{General observations}

Undisturbed clams observed on the reefs were never entirely shut, even when almost completely exposed by low tide, and often the valve opening or gape 
approached the maximum permitted by valve teeth, hinge ligaments, and mantle membrane. Presumably there is little if any passive tension in the adductor under these conditions (Abbott \& Lowy, 1956). Full valve closure may occur but it is probably rare. Field observations suggesting this are supported by the morphology of the crenulations at the valve edge, which do not intermesh well, and by the observation that in several instances portions of the valve broke when the adductor fully contracted in response to strong mechanical stimulation. This could only occur if considerable growth had occurred since the previous similar contraction.

Relative growth

Figure 2 plots valve weight, the difference between total weight and valve weight, measured viscera weight, and posterior adductor muscle weight against total body weight. The respective regression constants are 1.046 for valve weight, 0.904 for the difference between total and valve weight, 0.934 for viscera weight, and 0.915 for the posterior adductor between body weights of 6 and $100 \mathrm{~kg}$. In clams above $100 \mathrm{~kg}$ the adductor weight begins to level off and departs from the linear regression curve. In a clam weighing $100 \mathrm{~kg}$, valves would represent 73 per cent of

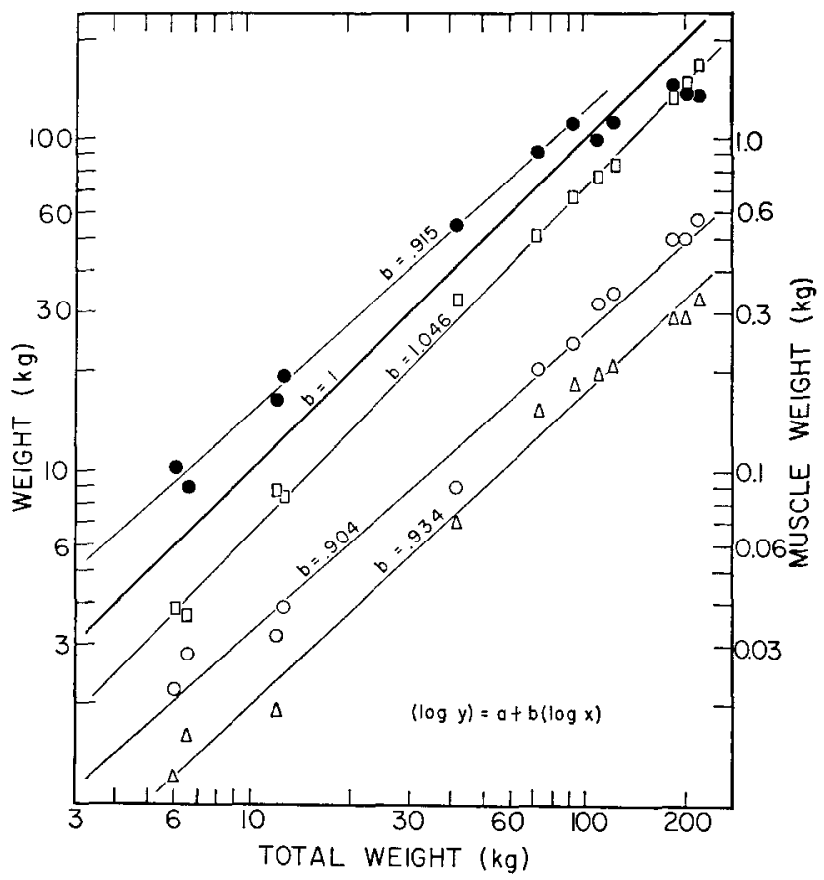

FIG. 2. Relation between total weight and weights of valves, viscera, and adductor muscle. Closed circles, - posterior adductor muscle weight; regression constant $=0.915$ and is linear up to total weights of $100 \mathrm{~kg}$. Open squares, $\square$, valve weight; regression constant $=1 \cdot 046$. Open circles, $O$, difference between valve weight and total weight; regression constant $=0.904$. Open triangles, $\triangle$, viscera weight; regression constant $=0.934$. For reference, the heavy line plots a regression constant of $1 \cdot 00$. 
the total weight, the viscera about 17.5 per cent, unaccounted fluid, about 9.5 per cent and the posterior adductor muscle, 1.2 per cent. In a $6-\mathrm{kg}$ clam the valves contribute about 57 per cent, viscera 25 per cent, unaccounted fluid 18 per cent and posterior adductor about 1.4 per cent. Apparently with increasing size, the valves become relatively heavier.

\section{Tension}

Figure 3 illustrates the results of a typical experiment with a 118-kg clam. Valve gape measured on the reef while the clam was in a relaxed undisturbed state was $26 \mathrm{~cm}$. This is equivalent to 156 per cent minimum in situ muscle length. After a single measurement of closing tension on the reef at a muscle length of 107 per cent, the clam was taken to the deck of the R/V Alpha Helix and the valves were slowly pulled open as described above. In the field, only single measurements were possible because of the time required for complete relaxation, but with smaller clams maintained for several days aboard ship, several measurements of closing tension were usually taken before pulling the valves in a final acute experiment.

Curve A of Fig. 3 plots total tension developed at the lip of the valve against estimated muscle length where 100 per cent represents muscle length at full closure. At about 153 per cent minimum length and tensions of over $170 \mathrm{~kg}$ the muscle ruptured. Curve $\mathrm{B}$ plots total tension at the muscle as calculated from lip tension. Curve $\mathrm{C}$ plots specific tension per $\mathrm{cm}^{2}$ using the measured cross sectional area of the isolated adductor as a constant reference. If the cross sectional area at 100 per cent length were used (100 per cent $=$ minimal $i$ situ length), all values of specific tension would be about 30 per cent larger. Curve D plots specific tension per $\mathrm{cm}^{2}$ using the estimated cross sectional area at each length as reference. Unless otherwise specified, all subsequent references to specific tension will use this latter variable reference. The large closed circle labelled $\mathrm{D}^{1}$ at 107.5 per cent muscle length represents the specific closing tension developed during active contraction on the reef. After measuring pulling tension, and removing and weighing viscera and valves, the force necessary to close the valves was determined as an estimate of ligament tension and other opening forces. The small closed circles in Fig. 3 (curve E) plot these total opening forces in terms of equivalent specific muscle tension. The opening forces become significant at closure, where they may reach values between $0.5 \mathrm{~kg} / \mathrm{cm}^{2}$ and $1 \mathrm{~kg} / \mathrm{cm}^{2}$. At lengths beyond 110 per cent ligament tension is relatively less significant, and was generally ignored.

Fig. 4 gives all length-tension values obtained. Tension is expressed in $\mathrm{kg} / \mathrm{cm}^{2}$ cross section at the specific muscle lengths, and length is given in terms of minimum in situ length at valve closure. Tensions obtained by pulling the valves are represented by the open circles, those obtained during active, normal closure are closed circles. The number of measurements possible on any one clam was limited, and there was scatter of values both between and sometimes within individuals. Mean pulling tension was estimated as $8 \cdot 0 \pm 1 \cdot 1 \mathrm{~kg} / \mathrm{cm}^{2}$ at 120 per cent minimum muscle length. In many, but not all clams, the contracted muscle ruptured before it 


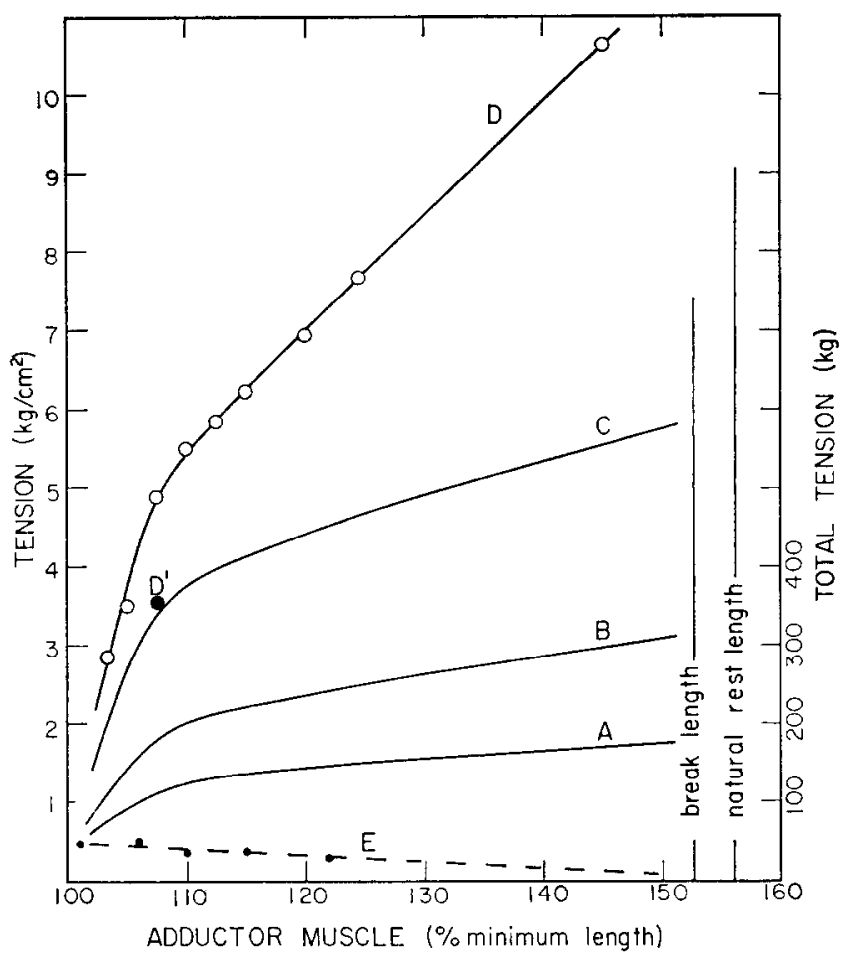

Fig. 3. Length-tension curves for Tridacna. Data from a single clam weighing $118 \mathrm{~kg}$ are plotted against in situ muscle length. 100 per cent length represents minimum in situ length. A. Total tension developed at edge of valves when contracted muscle was stretched. Subsequent curves are derived from these raw data; derived data points are shown only for curve $D$, open circles, $O$, and indicate the nature of the fit between measurements and curve for raw and derived data. B. Total tension developed by posterior adductor muscle. C. Adductor muscle tension per $\mathrm{cm}^{2}$ cross section at minimum dissected length ( $=76$ per cent minimum in situ length). D. Adductor muscle tension per $\mathrm{cm}^{2}$ cross section at muscle length of measurement. $\mathrm{D}^{1}$, closed circle, $\mathbf{e}$, active closing tension developed on the reef per $\mathrm{cm}^{2}$ adductor muscle cross section at length of measurement. E. Opening force of ligament and valve weight expressed in terms of $\mathbf{~ c m}^{2}$ adductor cross section at length of measurement. The units of curve $E$ are thus equivalent to curves $\mathrm{D}$ and $\mathrm{D}^{1}$. Rest length for the adductor muscle estimated from measurements on the undisturbed clam on the reef was 156 per cent of the minimum in situ length. The contracted muscle broke at 153 per cent minimum in situ length. Small closed circles, $\bullet$, total opening force of ligaments and shell in terms of specific muscle tension.

reached its nominal rest length. The mean break tension for those muscles which ruptured was $13.3 \pm 3.3 \mathrm{~kg} / \mathrm{cm}^{2}$ and the break length was $144 \pm 14.5 \%$ minimum length. If expressed in terms of cross section area at mean rest length $(165 \pm 21 \%$ in undisturbed clams) pulling tension at $120 \%$ becomes $11 \mathrm{~kg} / \mathrm{cm}^{2}$ and break tension becomes $15.2 \mathrm{~kg} / \mathrm{cm}^{2}$. At full or nearly full valve closure the adductor often continued to produce a net pulling force of about $3 \mathrm{~kg} / \mathrm{cm}^{2}$; the actual adductor 
tension must have been at least 20 per cent greater because the value does not allow for the opposed opening forces which were overcome (small closed circles).

Isometric closing tensions (large closed circles) showed much more scatter than the pulling tensions, and were appreciably lower for comparable muscle lengths in many instances (see also Fig. 3). In other cases, however, they fell in line with the pulling tensions, and the lower values may in part reflect incomplete or submaximal neural stimulation.

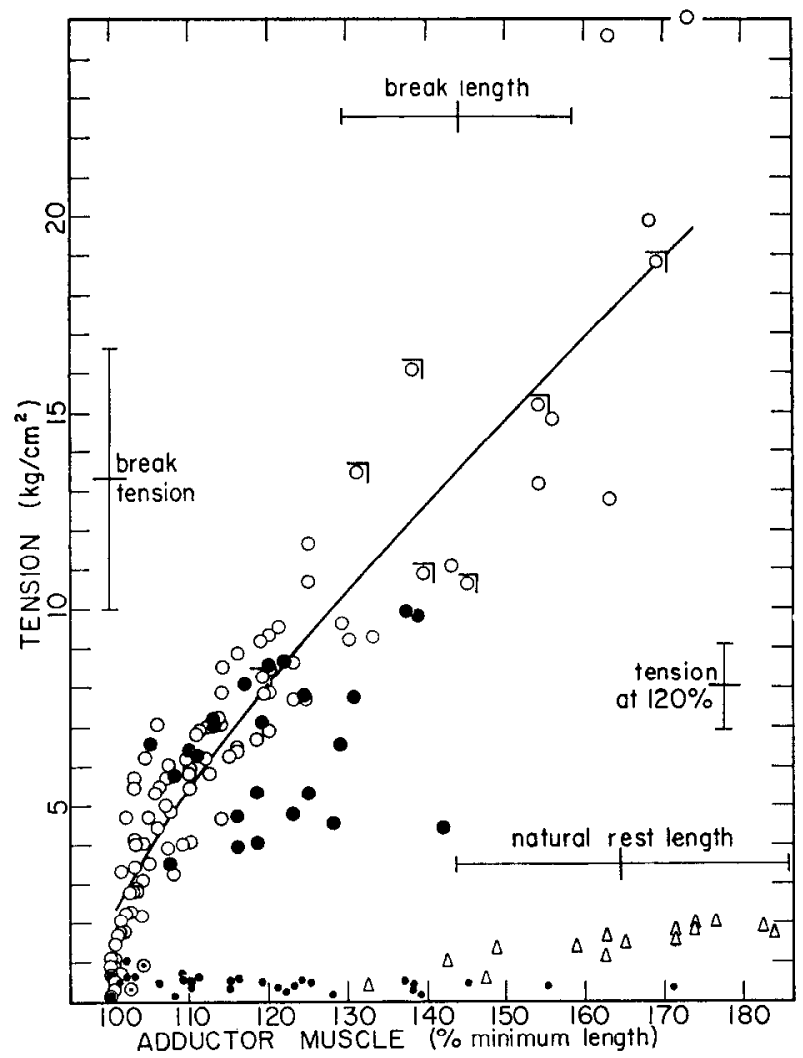

FIG. 4. Combined length-tension data from twelve Tridacna. Open circles, $O$, tension developed by contracted muscle when stretched. Large closed circles, - active closing tension developed when partially relaxed clam was stimulated and the adductor contracted to the indicated length. Small closed circles, $\bullet$, opening force of ligament and valve weight. Open triangles, $\triangle$, tension developed when anaesthetized clam was pulled open. All tension values expressed in terms of $\mathrm{cm}^{2}$ cross section of adductor muscle at lengths indicated. Length expressed in terms of minimum in situ length. Values of mean break tension, mean break length, mean rest length, and tension at 120 per cent minimum length are indicated together with standard deviations of the sample mean. Right angles, 7 , above data points indicate maximum length-tension measured for that particular clam before muscle rupture. The curve is drawn by eye through pulling tensions only. 
The triangles of Fig. 4 are taken from one experiment in which the clam was anaesthetized with $0.2 \%$ MS 222 , and represent pulling tensions remaining in the largely anesthetized posterior adductor and other soft parts. Clearly the muscle was not completely relaxed, because the passive gape of the anaesthetized clam was equivalent to only 125 per cent rather than 165 per cent muscle length.

Fig. 5 plots (a) total maximum tension developed at the value edge, (b) the tension developed at the muscle at 120 per cent minimum length, (c) the total

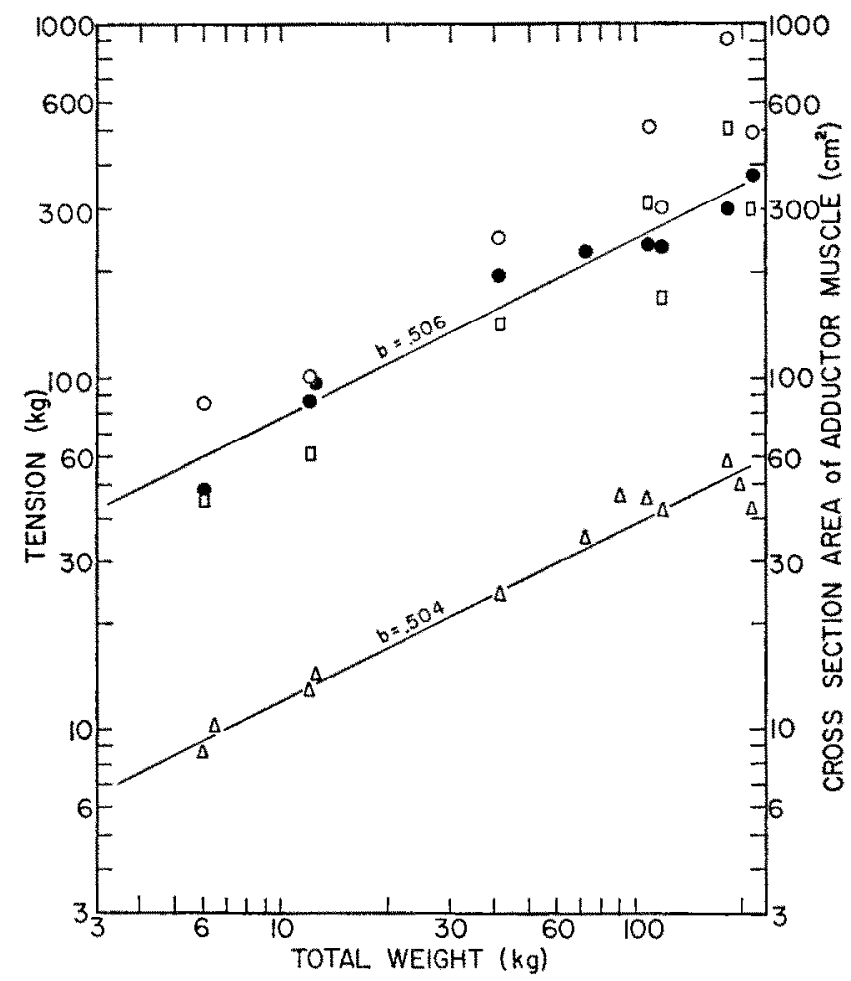

Fig. 5. Relation between total weight and tension and muscle cross section. Open circles, $O$, maximum tension developed at muscle. Open squares, $\square$, maximum tension developed at valve edge. Closed circles, $\bullet$, tension developed at 120 per cent minimum in situ muscle length. Open triangles, $\Delta$, cross-section area of posterior adductor muscle at minimum in situ length. Regression constants for tension at 120 per cent length and cross section area are given. The small difference in regression constants is not statistically significant.

maximum tension developed at the muscle, and (d) the muscle cross section area at 100 per cent muscle length. Tension developed remains proportional to the muscle cross section over the full range of body weights, indicating that in so far as isometric tension is concerned, muscle physiology does not alter over a size factor of 36. The contracted muscle is capable of supporting even the largest clam's weight: 
tensions of $500 \mathrm{~kg}$ at the muscle or $300 \mathrm{~kg}$ at the valve edge were usual for clams weighing $100-200 \mathrm{~kg}$.

\section{DISCUSSION}

Our results indicate that the posterior adductor muscle of Tridacna gigas acts like other molluscan adductor muscles (Marceau, 1909; Abbott \& Lowy, 1956; Abbott \& Lowy, 1958). There is no evidence for appreciable passive resting tension at muscle lengths attained within the animal, while over that same range, active tension increases with length. Specific pulling tensions developed at 120 per cent lie within the range of maximum specific tensions reported by Marceau (1909) for a variety of molluscs when expressed in comparable terms. Marceau's values are for maximal tensions, which occur only at longer in situ muscle lengths, but he calculated specific tensions with respect to the cross section area at minimum in situ length. Thus our estimates calculated for the cross section area at 120 per cent length must be reduced by about 16 per cent for accurate comparison. (Compare Table 1 with Fig. 4 for values for Tridacna). Much of our data, like those of Marceau, are "pulling tensions" determined by stretching a contracted or contracting muscle to a new and longer length. The state of the muscle under these conditions is undoubtedly different from that which obtains when contraction occurs at the measurement length, e.g. closing or isometric tension. Our maximum "closing tension" values at any given length were close to pulling tensions, however, and in the one or two instances when measured near natural rest length, approached $10 \mathrm{~kg} / \mathrm{cm}^{2}$ (Fig. 4). These closing tensions are generally greater than those obtained by Abbott \& Lowy $(1956,1958)$ from actively contracting isolated anterior byssus retractor muscle (ABRM) of Mytilus, posterior adductor of Pinna, and pharynx retractor of Helix. Thus neither the large size of the clam nor its passive behavior is associated with a reduction in the ability of the adductor to develop tension.

The selective advantages of high closing forces is not altogether clear, but perhaps can be partially understood in terms of the need to move large masses of water relatively rapidly during sudden valve closure. For the clam exposed at low tide, this is a significant weight, and even for the immersed animal, the volume involved is of such magnitude that the necessary forces must be appreciable. Measurements relating tension to the speed of shortening would be desirable, but were not made in this study. Nor were the separate properties of the two components of the adductor, the white and the gray, examined.

The observation that muscles often ruptured before maximum rest lengths were obtained when pulled open tells little about the nature of the individual muscle fiber or its contractile machinery. With such a compound structure, neither the state of contraction, length, or critical tension can be determined for the individual muscle fibers which break.

One of the most persistent myths surrounding the giant clam is that it traps the unwary pearl diver who may insert his arm or leg within the valves. We cannot comment on the origin or accuracy of the story, nor did we test it experimentally. 


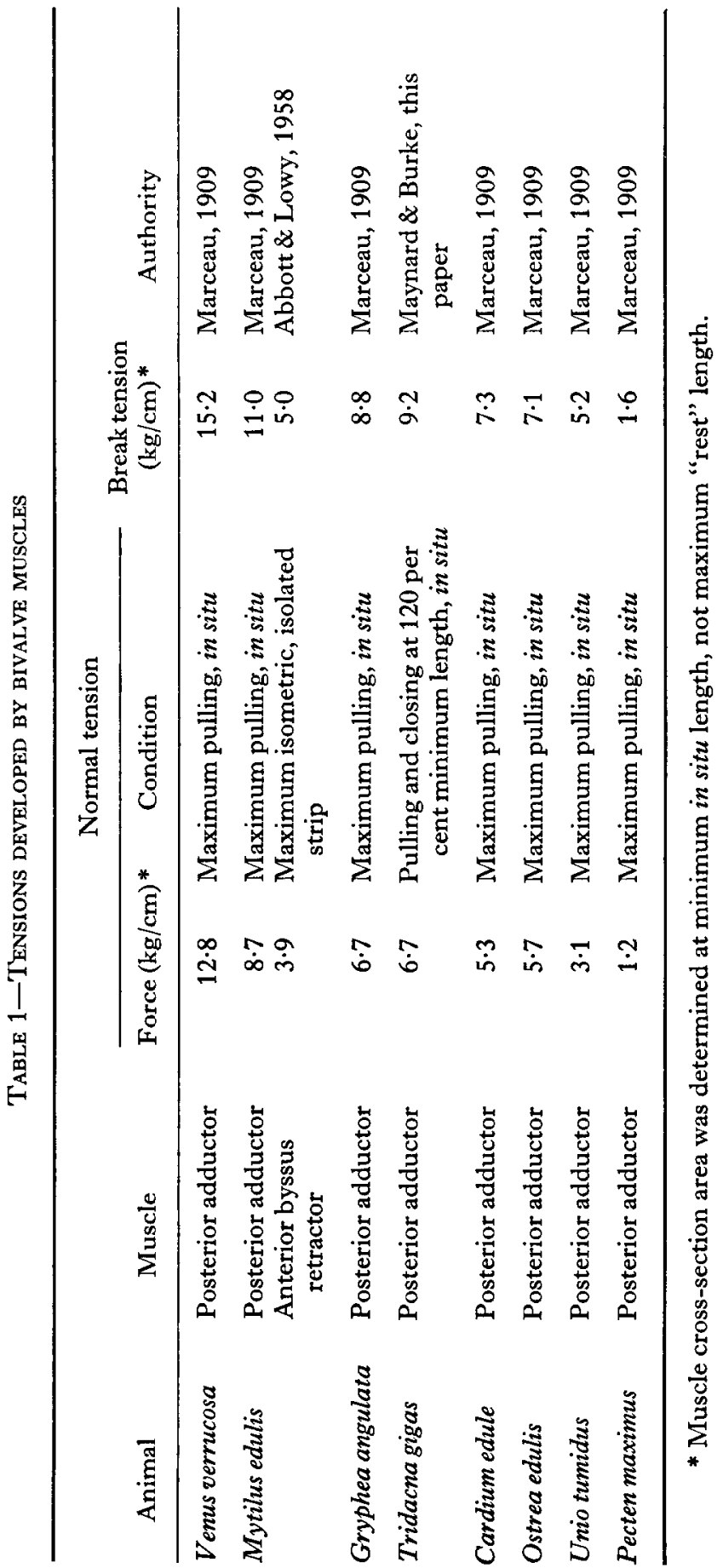


Nevertheless, it is clear from our measurements that it would be exceedingly difficult to withdraw a limb once the valves of a reasonably large clam (perhaps $50 \mathrm{~kg}$ or more) closed upon it. Although the valves will often begin to open within a few tens of seconds after the cessation of a relatively brief mechanical stimulus, a moving object such as a hand or foot within the mantle cavity would surely provide continuing stimulation and tend to evoke full maintained muscle contraction. Even with nearly complete closure tensions may reach $100 \mathrm{~kg}$ at the edge of the valve. Valve closure often is not particularly rapid, however, and a hand can easily be inserted and withdrawn from the mantle cavity before contraction is complete. Thus, only if an individual fell into the mantle cavity or was prevented from withdrawing immediately, might he be trapped by the closing valves.

Acknowledgements-The experiments reported here were performed aboard the $\mathrm{R} / \mathrm{V}$ Alpha Helix while anchored off Flinder's Island, north Queensland, Australia. We wish to express appreciation to T. H. Bullock and P. F. Scholander for suggestions regarding measurement procedures, and to K. Kelly, R. McConnaughey and B. Schmidt-Nielsen for invaluable assistance in collecting and handling the larger specimens. This work was supported in part by National Science Foundation Grant NSF-GB-4259 and by USPHS Grant NIH-NB-06017-01.

\section{REFERENCES}

Аввотт B. C. \& Lowy J. (1956) Mechanical properties of Pinna adductor muscle. f. mar. biol. Ass. U.K. 35, 521-530.

Аввотт B. C. \& Lowy J. (1958) Mechanical properties of Helix and Mytilus muscle. $\mathcal{F}$. Physiol. Lond. 141, 398-407.

MARCEAU F. (1909) Recherches sur la morphologie, l'histologie et la physiologie comparée des muscles adducteurs des mollusques acéphales. Archs zool. exp. et gén. 5th scr. 2, 296469.

Rosewater J. (1965) The family Tridacnidae in the Indo-Pacific. Indo-Pacific Mollusca, Vol. 1, No. 6, Acad. Nat. Sci., Philadelphia, pp. 347-394.

Vaillant L. (1865) Recherches sur la famille des Tridacnidés. Ann. des Sc. nat. Zoologie, 5th ser. 4, 65-172.

Key Word Index-Muscle tension; clam muscle fibres; Tridacna gigas; tension; posterior adductor muscle. 